\title{
Functional Evaluation of Levator Scapulae Tendon to Supraspinatus in Adult Brachial Plexus Injuries
}

\author{
Venkata Koteswara Rao Rayidi ${ }^{1} \quad$ Srikanth $\mathrm{R}^{1} \quad$ Jagadish Kiran C.V. Appaka ${ }^{1}$ \\ ${ }^{1}$ Department of Plastic and Reconstructive Surgery, Nizams \\ Institute of Medical Sciences, Hyderabad, Telangana, India \\ Address for correspondence Appaka C.V. Jagadish Kiran, \\ M. Ch, Department of Plastic And Reconstructive Surgery, Nizams \\ Institute Of Medical Sciences, Hyderabad, Telangana, 500082, India \\ (e-mail: drjkplasticsurgery@gmail.com).
}

Indian J Plast Surg:2021;54:38-45.

\begin{abstract}
Introduction Brachial plexus injuries are severe life-altering injuries. The surgical method to restore shoulder abduction in adult upper brachial plexus injuries involves the usage of nerve grafts and nerve transfers targeting the suprascapular and/or the axillary nerve. When the primary nerve surgery has been unsuccessful or recovery has been incomplete or with a late presentation, muscle transfer procedures are needed to provide or improve shoulder abduction. Levator scapulae to supraspinatus is a transfer to improve shoulder abduction in posttraumatic brachial plexus injuries.

Material and Methods The study included 13 patients with the age ranging from 17 to 47 years with a mean age of 30 years. All these patients had preop shoulder abduction of Medical Research Council (MRC) grade $\leq 3$. All had a minimum of MRC grade 4 of active elbow flexion. Eleven patients had primary surgery. Only patients with a minimum of 1 year postoperative follow-up were included. All 13 patients underwent levator scapulae transfer only.

Results All patients had a stable shoulder postoperatively. The average increase in active shoulder abduction was from $6.15^{\circ}$ (median: $0^{\circ}$ ) preoperatively to $61.92^{\circ}$ (median: $\left.60^{\circ}\right)$, with an average gain in shoulder abduction of $49.61^{\circ}$ (median: $50^{\circ}$ ).

Conclusions Transfer of levator scapulae tendon to the supraspinatus is an option to improve shoulder abduction in posttraumatic brachial plexus. In conditions where

\section{Keywords}

- brachial plexus injuries

- levator scapulae

- supraspinatus supraspinatus alone is not functioning, levator scapulae is the best available transfer, considering its strength and maintaining the form of the shoulder unlike trapezius transfer. In patients with previous surgery where supraspinatus has recovered partially but not functionally significant, this tendon transfer can be considered for the augmentation of the existing shoulder abduction.
\end{abstract}

\section{Introduction}

Brachial plexus injuries are severe life-altering injuries. The surgical method to restore shoulder abduction in patients with injuries of the upper plexus in adults involves the usage of nerve grafts and nerve transfers targeting the

published online

February 8, 2021
DOI https://doi.org/

10.1055/s-0040-1721865

ISSN 0970-0358. suprascapular and or the axillary nerve. Shoulder abduction being affected by multiple muscle groups and selective neurotization may not give normal shoulder function. So, even when the elbow function has been restored, poor shoulder function may need further procedures to optimize shoulder abduction. Nonfunctioning shoulders can 
also be surgically fused or a trapezius transfer done to provide some movement or, at least, stability to prevent inferior subluxation; this can also improve elbow function by providing the innervated elbow flexor a stable fulcrum to exert its action..$^{1-4}$ Obstetric plexus injuries (OBPI) following birth injury is a special subset where the transfer of the latissimus dorsi has been done with good return of shoulder abduction. ${ }^{5}$

Since a previous use of the spinal accessory nerve (SAN) denervates the lower and possible middle part of the trapezius muscle, its use may not be prudent in muscle transfer, and the common attempt to improve joint function by an isolated trapezius transfer alone leads to an obligatory proximal migration of the humeral head. ${ }^{6}$ The decreased distance between the humeral head and acromion results in mechanical impingement as well as decreased trapezius lever arm. The consequence is ineffective shoulder abduction and flexion. Shoulder fusion prevents lying down at night on the same side, and on account of the unstable nature of the fusion, it may give considerable morbidity in young adults.

Narakas has described levator scapulae tendon transfer in the palsy of spinati, elongated with a periosteal strip in children, fascia lata or artificial tendon/ligament in adults, passing under the acromion. This modification of Saha's method is quite efficient in the presence of a strong deltoid. ${ }^{7}$

The aim of the study is to evaluate the functional improvement of shoulder abduction after transfer of levator scapulae tendon to supraspinatus in patients with traumatic brachial plexus injuries either when the primary nerve surgery has been unsuccessful or recovery has been incomplete

\section{Subjects and Methods}

The study included 13 patients with the age ranging from 17 to 47 years with a mean age of 30 years from February 2017 to February 2020 (-Tables $\mathbf{1}$ and $\mathbf{2}$ ). All these patients had preop shoulder abduction of Medical Research Council (MRC) grade $\leq 3$. All had a minimum of MRC grade 4 of active elbow flexion. Eleven patients underwent primary surgery, seven were neurotization to supraspinatus nerve, using SAN in five patients and phrenic nerve in two patients (- Table 3 ). In these patients, either shoulder abduction is absent or with minimal abduction, which is functionally not significant. Only patients with a minimum of 12 months postoperative follow-up were included. All 13 patients underwent only a transfer of the levator scapulae tendon to the supraspinatus.

\section{Operative Technique}

Since levator scapulae is a deep-seated muscle, preoperative testing is difficult. Clinically, levator scapulae muscle function is elicited by squaring of scapula/shoulders ( - Fig. 1). Intraoperative nerve stimulation is used to confirm the activity of the muscle before transfer.

The surgery was done under general anesthesia with the patient in a lateral decubitus position, so that the involved shoulder is well accessible (-Fig. 2). The ipsilateral upper extremity was prepared and draped accordingly to allow shoulder positioning during surgery; a protective bean bag was placed between the thighs. No muscle relaxation was permitted till complete harvest of the levator scapulae muscle. A bipolar nerve stimulator was used during surgery to confirm the strength of innervation of the levator scapulae muscle.

Infiltration of all skin incisions was done using 1 in $2,00,000$ adrenaline saline solution. The first incision was made along the paraspinal line of upper back, 1 inch from the midline. This facilitates exposure of the lower and middle fibers of the trapezius muscle. This was retracted medially in the middle part to expose the levator scapulae muscle. The insertion of this muscle was followed down along the medial border of the scapula to enable a periosteal extension to be harvested, as this would give sufficient length

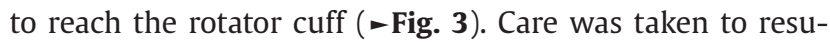
ture the detached rhomboideus muscle after sectioning and elevating the levator muscle tendon complex. A subtrapezius tunnel was created from the upper end of scapulae toward acromion process all along the supraspinous fossa (-Fig. 4).

The second incision, curved, was given over deltoid region. Origin of the middle portion of the deltoid was disinserted to reach subacromial bursa and identification of the supraspinatus tendon. Through the subtrapezius tunnel, levator scapulae tendon was directed to supraspinatus tendon and sutured with 2-0 polypropylene/nylon sutures, keeping the upper limb in a minimum of 90 degrees of abduction ( - Fig. $\mathbf{5}$ ). Sectioned deltoid muscle fibers were reanchored to acromion process. Closure of the skin incisions was done in two layers using 3-0 poliglecaprone and skin clips for the skin.

The limb was splinted with the shoulder between 90 and 120 degrees of abduction, using a preoperatively prepared removable splint for a period of 6 weeks ( - Fig. 6 ). Thereafter, the splint was removed for three sessions (15 minutes each) of shoulder abduction, eliminating gravity for 2 weeks; from 8 to 10 weeks, the sessions were increased to six times a day. From 10 weeks, intermittent abduction against gravity was encouraged. Only night splint was advised after 3 months for a further period of 3 months.

\section{Results}

Results of the surgery have been assessed according to the scale of assessment as shown in ( - Table 4 ).

\section{Active ROM for Shoulder Abduction after Levator Scapulae Transfer ( - Tables 5 and 6 )}

Median preop shoulder abduction: $0^{\circ}$

Median postop shoulder abduction: $60^{\circ}$

Median gain in shoulder abduction: $50^{\circ}$

\section{Complications}

One patient had a postoperative hematoma on the first postoperative day (POD), for which evacuation of hematoma was done. One patient showed no result due to poor 
Table 1 Patient details, preop delay, type of injury, primary surgery, shoulder abduction

\begin{tabular}{|c|c|c|c|c|c|c|c|}
\hline \multirow{2}{*}{$\begin{array}{l}\text { S. } \\
\text { no. }\end{array}$} & \multirow[t]{2}{*}{ Age/sex } & \multicolumn{2}{|c|}{ Preop delay } & \multirow[t]{2}{*}{ Type of injury } & \multirow[t]{2}{*}{ Any primary surgery done } & \multicolumn{2}{|c|}{ Shoulder abduction } \\
\hline & & $\begin{array}{l}\text { Time } \\
\text { since } \\
\text { injury }\end{array}$ & $\begin{array}{l}\text { Time } \\
\text { since first } \\
\text { surgery. }\end{array}$ & & & $\begin{array}{l}\text { Preop } \\
\text { against } \\
\text { gravity }\end{array}$ & $\begin{array}{l}\text { Postop } \\
\text { against } \\
\text { gravity }\end{array}$ \\
\hline 1 & $21 / \mathrm{M}$ & 2 years & - & Trauma-C5 lesion & Nil-late presentation & 30 & 110 \\
\hline 2 & $37 / \mathrm{M}$ & - & 3 & Trauma-pan plexus lesion & $\begin{array}{l}\text { Late presentation-FFMT for elbow } \\
\text { flexion and wrist extension }\end{array}$ & 0 & 15 \\
\hline 3 & $25 / \mathrm{M}$ & $\begin{array}{l}9 \\
\text { months }\end{array}$ & - & $\begin{array}{l}\text { Ipsilateral compound clavicle \& } \\
\text { fracture scapula }\end{array}$ & Nil & 0 & 155 \\
\hline 4 & $23 / \mathrm{M}$ & - & & Trauma-pan plexus lesion & $\begin{array}{l}\text { Neurotisation (SAN-MCN cable } \\
\text { grafts), tendon repair, CMC], } \\
\text { PIPJ arthrodesis }\end{array}$ & 0 & 40 \\
\hline 5 & $31 / \mathrm{M}$ & - & 3 years & Trauma-T1 hand & $\begin{array}{l}\text { Neurotization (phrenic nerve to } \\
\text { SSN, SAN to MCN), Steindler's } \\
\text { procedure, tendon transfers for } \\
\text { wrist extension. }\end{array}$ & 0 & 50 \\
\hline 6 & $20 / \mathrm{M}$ & - & 5 years & $\begin{array}{l}\text { Trauma-pan } \\
\text { plexus lesion }\end{array}$ & $\begin{array}{l}\text { FFMT for elbow flexion and wrist } \\
\text { extension. }\end{array}$ & 0 & 60 \\
\hline 7 & $17 / \mathrm{M}$ & - & $\begin{array}{l}20 \\
\text { months }\end{array}$ & Trauma-C5, C6, C7 lesion & $\begin{array}{l}\text { Neurotisation } \\
\text { SAN to SSN } \\
\text { Oberlin } 1 .\end{array}$ & 10 & 45 \\
\hline 8 & $30 / \mathrm{M}$ & - & 2 years & Trauma-C5, C6, C7 lesion & Neurotization SAN to SSN. & 0 & 60 \\
\hline 9 & $32 / \mathrm{M}$ & - & 3 years & Trauma-C5, C6, C7 lesion & FFMT for elbow flexion. & 0 & 60 \\
\hline 10 & $47 / \mathrm{M}$ & - & 2 years & Trauma-pan plexus lesion & SAN to SSN; 3, 4 ICN to MCN. & 0 & 60 \\
\hline 11 & $37 / \mathrm{M}$ & - & 6 years & $\begin{array}{l}\text { Trauma-C5, } \\
\text { C6, C7 lesion }\end{array}$ & $\begin{array}{l}\text { Neurotization (phrenic nerve to } \\
\text { SSN, SAN-MCN). }\end{array}$ & 30 & 80 \\
\hline 12 & $41 / \mathrm{M}$ & - & 15months & Trauma-C5, C6 lesion & $\begin{array}{l}\text { Neurotization } \\
\text { (SAN to SSN, Somsak, Oberlin). }\end{array}$ & 0 & 30 \\
\hline 13 & 29/M & - & 13 months & Trauma-C5, C6 lesion & $\begin{array}{l}\text { Neurotization SAN to SSN, Oberlin } \\
1 \& 2 \text {. }\end{array}$ & 10 & 40 \\
\hline
\end{tabular}

Abbreviations: BPI, brachial plexus injury; CMCP, carpometacarpal joint; FFMT, free functional muscle transfer; ICN, intercostal nerves; PIPJ, proximal interphalangeal joint; SAN, spinal accessory nerve; SSN, suprascapular nerve.

Table 2 Type of lesion

\begin{tabular}{|l|l|l|l|l|}
\hline Type of lesion & Isolated C5 lesions & $\begin{array}{l}\text { Upper plexus (C5-6) } \\
\text { lesions }\end{array}$ & $\begin{array}{l}\text { Extended upper plexus (C5-7) } \\
\text { lesions }\end{array}$ & Pan plexus \\
\hline No. of patients & $\mathbf{2}$ & $\mathbf{2}$ & $\mathbf{5}$ & $\mathbf{4}$ \\
\hline
\end{tabular}

Table 3 Previous surgery where SAN has been used for extraplexus neurotization

\begin{tabular}{|c|c|c|c|c|}
\hline $\begin{array}{l}\text { Type of } \\
\text { lesion }\end{array}$ & $\begin{array}{l}\text { Isolated } \\
\text { C5 lesion }\end{array}$ & Upper plexus (C5-6) lesions & $\begin{array}{l}\text { Extended upper plexus (C5-7) } \\
\text { lesions }\end{array}$ & Pan plexus lesions \\
\hline $\begin{array}{l}\text { Previous } \\
\text { surgery }\end{array}$ & 2 & 2 & 5 & 4 \\
\hline $\begin{array}{l}\text { Type of } \\
\text { previous } \\
\text { surgery }\end{array}$ & - & $\begin{array}{l}1 \text { patient: underwent } \\
\text { SAN-SSN neurotisation. } \\
\text { 1 patient: } \\
\text { SAN-SSN neurotisation \& triceps } \\
\text { motor branch transfer to axillary } \\
\text { nerve (Somsak transfer) }\end{array}$ & $\begin{array}{l}\text { 2 patients: underwent } \\
\text { SAN-SSN neurotisation. } \\
2 \text { Patients: phrenic nerve- } \\
\text { SSN neurotisation. in whom } \\
\text { SAN-MCN neurotization done } \\
\text { with cable grafts. } \\
1 \text { patient: } \\
\text { FFMT for elbow flexion. }\end{array}$ & $\begin{array}{l}\frac{1 \text { patient: }}{\text { SAN-SSN neurotization \& 3,4 ICN-MCN }} \\
\text { neurotisations. } \\
\text { 1 patient: } \\
\text { SAN-MCN neurotisation with cable } \\
\text { grafts } \\
2 \text { patients: } \\
\text { FFMT for elbow flexion and wrist exten- } \\
\text { sion with SAN }\end{array}$ \\
\hline
\end{tabular}

Abbreviations: ICN-MCN neurotization: intercostal nerve coaptation with musculocutaneous nerve; SAN-SSN neurotization: spinal accessory nerve coaptation with nerve to suprascapular; SAN-MCN neurotization: spinal accessory nerve coaptation with musculocutaneous nerve. 


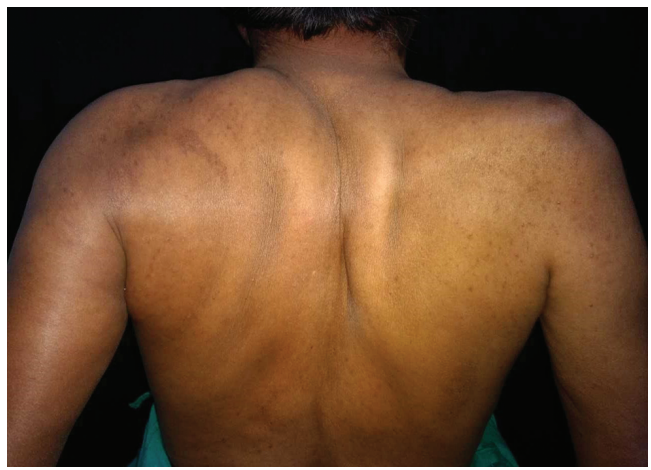

Fig. 1 Picture demonstrating squaring of scapula/shoulder.

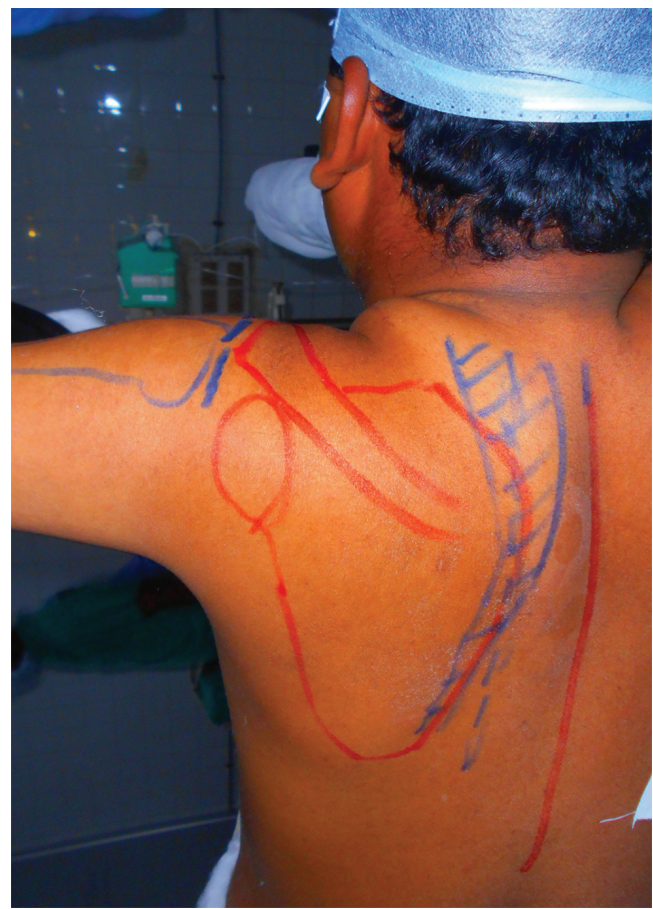

Fig. 2 Preoperative anatomical depiction of levator scapulae muscle.

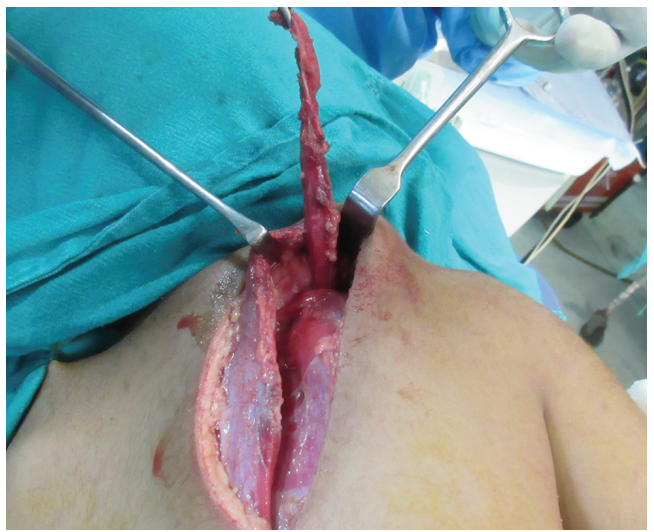

Fig. 3 Intraoperative picture demonstrating harvested levator scapulae muscle.

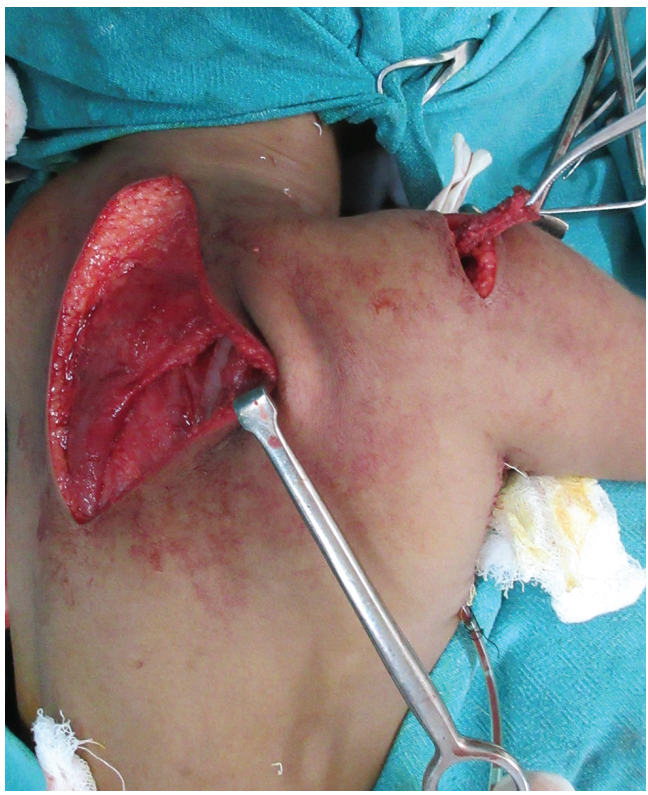

Fig. 4 Intraoperative picture demonstrating levator scapulae muscle directed toward the supraspinatus tendon through the subtrapezius tunnel.

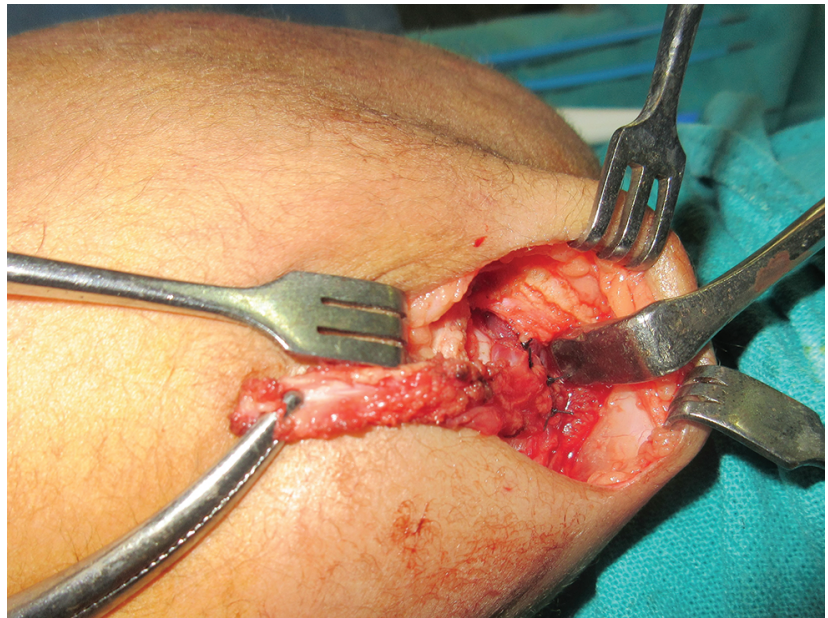

Fig. 5 Intraoperative picture demonstrating levator scapulae muscle sutured to supraspinatus tendon.

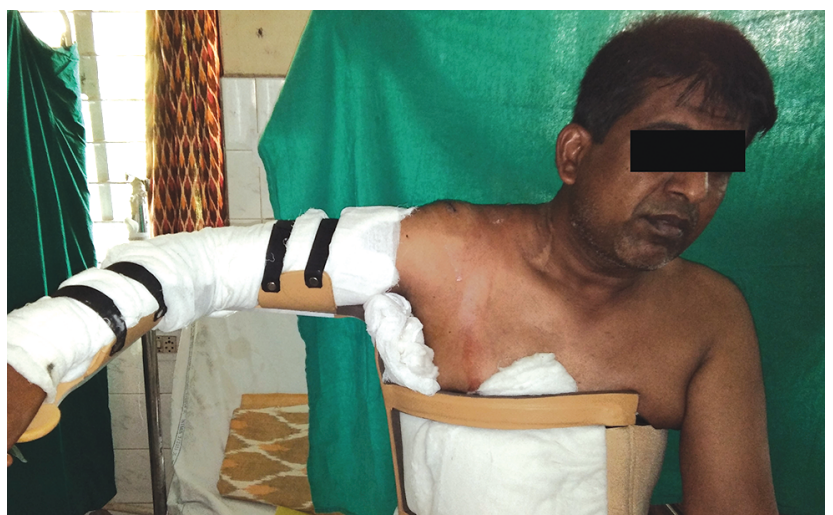

Fig. 6 Postoperative picture showing shoulder splinted in $90^{\circ}$ abduction. 
compliance postoperatively in view of head injury. There were no infections, no wound dehiscence, and no seroma formation.

\section{Discussion}

The standard muscle transfer for shoulder abduction has been the transfer of the trapezius to the deltoid insertion, usually with a segment of the acromion to enable a secure fixation. The common attempt to improve joint function by an isolated trapezius transfer alone leads to an obligatory

Table 4 Scale for assessment of results following levator scapulae transfer

\begin{tabular}{|l|l|l|l|}
\hline & $\begin{array}{l}\text { MRC } \\
\text { grade }\end{array}$ & ROM (in degrees) & Gravity \\
\hline Good & M4 & 75 & Against gravity \\
\hline Fair & M3 & $30-75$ & Eliminating gravity \\
\hline Poor & $<$ M2 & $<30$ & Eliminating gravity \\
\hline
\end{tabular}

Abbreviation: ROM, range of motion. proximal migration of the humeral head. The decreased distance between the humeral head and acromion results in mechanical impingement as well as decreased trapezius lever arm. The consequence is ineffective shoulder abduction and flexion. This is also relatively contraindicated in patients who had underwent an unsuccessful SAN to SSN transfer in the past.

Due to its very proximal innervation (cervical plexus C4, C5), levator scapulae muscle is likely to be functioning even in severe upper plexus lesions. This fact allows us to utilize this transfer as a glenohumeral intrinsic stabilizer even when no latissimus dorsi is available. This has also proven useful in obstetric palsy to improve shoulder abduction. Permanent deficiency in abduction of the arm seen after brachial plexus injury may be corrected by a levator scapulae transposition onto the supraspinatus. ${ }^{7}$

The levator scapulae muscle is innervated by nerves exiting from the C4 and C5 roots (sometimes C3 also) as the dorsal scapular nerve; this also supplies the rhomboideus muscles, thus making this a potential donor for tendon transfer even in avulsion upper brachial plexus injuries.

Table 5 Results

\begin{tabular}{|c|c|c|c|c|c|c|c|}
\hline \multirow[t]{2}{*}{ S. no: } & \multirow[t]{2}{*}{ Age/sex } & \multirow[t]{2}{*}{ Nature of injury } & \multicolumn{2}{|c|}{$\begin{array}{l}\text { Shoulder abduction in } \\
\text { degrees }\end{array}$} & \multicolumn{2}{|c|}{ MRC Grade } & \multirow{2}{*}{$\begin{array}{l}\text { Postoperative } \\
\text { improvement in range } \\
\text { of shoulder abduction } \\
\text { in degrees. }\end{array}$} \\
\hline & & & $\begin{array}{l}\text { Preop } \\
\text { against } \\
\text { gravity }\end{array}$ & $\begin{array}{l}\text { Postop } \\
\text { against } \\
\text { gravity }\end{array}$ & Preop & Postop & \\
\hline 1 & $21 / \mathrm{M}$ & C5 lesion & 30 & 110 & M2 & M4 & 80 \\
\hline 2 & $37 / \mathrm{M}$ & Pan plexus lesion & 0 & 15 & M0 & M1 & 15 \\
\hline 3 & $25 / \mathrm{M}$ & C5 lesion & 0 & 155 & M3 & M4 & 155 \\
\hline 4 & $23 / \mathrm{M}$ & Pan plexus lesion & 0 & 40 & $\mathrm{M} 2$ & M3 & 40 \\
\hline 5 & $31 / \mathrm{M}$ & $\begin{array}{l}\text { Trauma-C5, C6, } \\
\text { C7 Lesion }\end{array}$ & 0 & 50 & M1 & M3 & 50 \\
\hline 6 & $20 / \mathrm{M}$ & Pan plexus lesion & 0 & 60 & M1 & M3 & 60 \\
\hline 7 & $17 / \mathrm{M}$ & C5, C6, C7 lesion & 10 & 45 & M1 & M3 & 35 \\
\hline 8 & $30 / \mathrm{M}$ & C5, C6, C7 lesion & 0 & 60 & M0 & M3 & 60 \\
\hline 9 & $32 / \mathrm{M}$ & C5, C6, C7 lesion & 0 & 60 & $\mathrm{M} 2$ & M3 & 60 \\
\hline 10 & $47 / M$ & Pan plexus lesion & 0 & 60 & M0 & M2 & 60 \\
\hline 11 & $37 / \mathrm{M}$ & C5, C6, C7 lesion & 30 & 80 & $\mathrm{M} 2$ & M4 & 50 \\
\hline 12 & $41 / \mathrm{M}$ & C5, C6 lesion & 0 & 30 & M2 & M3 & 30 \\
\hline 13 & $29 / M$ & C5, C6 lesion & 10 & 40 & M1 & M3 & 30 \\
\hline
\end{tabular}

Abbreviation: MRC, Medical Research Council.

Table 6 Outcome according to the evaluation scale described above

\begin{tabular}{|l|l|l|l|l|}
\hline & Isolated C5 lesion & Upper plexus (C5-6) lesions & Extended upper plexus (C5-7) lesions & Pan plexus \\
\hline Good & 2 & - & - & - \\
\hline Fair & - & 2 & 5 & 3 \\
\hline Poor & - & - & - & 1 \\
\hline
\end{tabular}


Levator scapulae is a type 1 muscle with a broad muscle belly after arising as four tendinous slips from the cervical vertebra ( - Fig. 7). Through its insertion onto the medial upper corner of the scapula, it elevates the scapulae and rotates the inferior angle of scapula medially. The vector of pull of levator scapulae muscle transfer is from above, contrary to latissimus dorsi which is from below.

Study of the excursion of the potential muscles around the shoulder reveals the levator scapulae has $15.3 \mathrm{~cm}$ of excursion, far above that for the trapezius muscle, although its relative tension is $1.7 \%$, lower than other shoulder muscles. ${ }^{8}$ Due its excursion and vector of pull being similar to supraspinatus and it being spared in majority of the plexus injuries, this muscle can be considered as a potential donor.

Aziz, Singer, and Wolff reviewed 27 patients of brachial plexus injury treated by transfer of trapezius. They used a modification of the surgical technique described by Mayer (1927) and Bateman (1955) and amended by Saha (1967). The average gain in shoulder abduction was 45.4 degrees with a range of 20 to 120 degrees. ${ }^{9}$

Ruhmann et al included 31 patients with paralysis of the deltoid and supraspinatus. Trapezius transfer was performed according to the method of Saha. Average increase in active abduction was from $7.3^{\circ}\left(0-45^{\circ}\right)$ to $39^{\circ}\left(25-80^{\circ}\right)$ at the latest review $^{10}$

Kotwal et al treated 27 patients with deltoid paralysis by trapezius transfer using Saha's technique in poliomyelitis and brachial plexus injury patients and found that the average gain in active abduction was 60 degrees in the brachial plexus group and 45 degrees in the poliomyelitis group $^{11}$

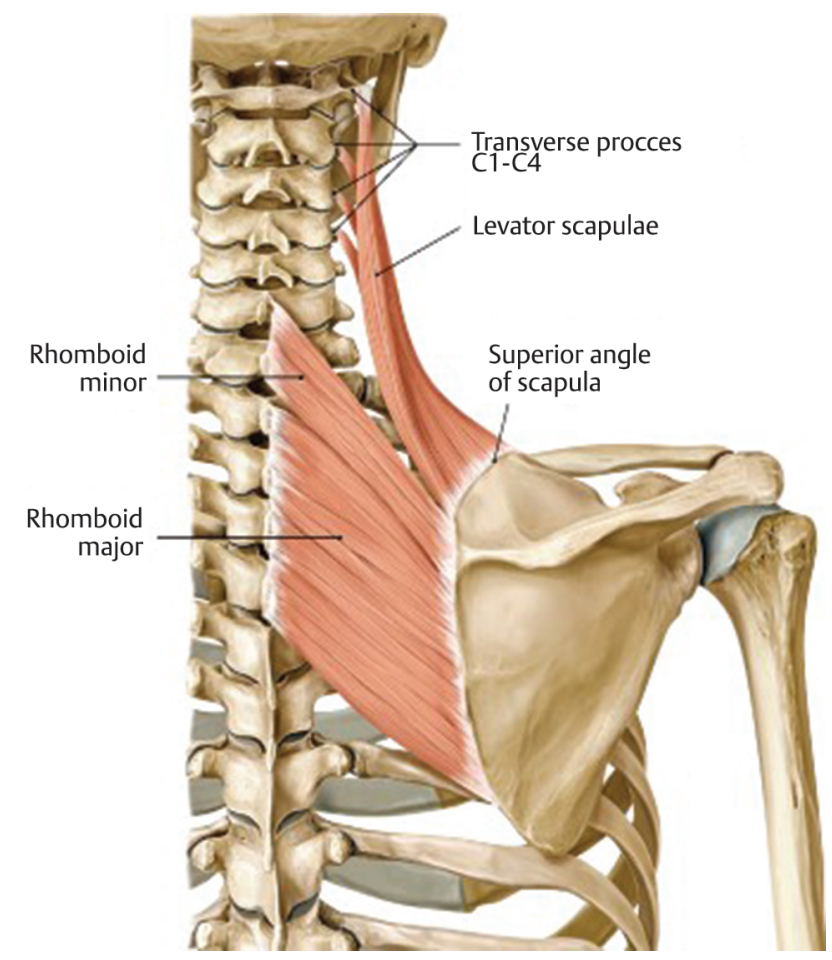

Fig. 7 Anatomy of levator scapulae muscle.
Singh et al treated eight patients of posttraumatic brachial plexus injury with insufficient shoulder abduction by trapezius muscle transfer, in which the trapezius was dissected and detached from its insertion along with the periosteum and sutured to the insertion of the deltoid muscle. The average increase in active abduction of shoulder was from 13.7 degrees ( 0 to 35 degrees) preoperatively to 116 degrees (45 to 180 degrees) postoperatively and of shoulder flexion from 24.3 degrees (15 to 30 degrees) to 107 degrees (90 to 180 degrees). ${ }^{12}$

In our study, 11 out of 13 patients had undergone a previous surgery where SAN has been used for extraplexus neurotization, making the trapezius transfer a relative contraindication. Further levator scapulae do not distort shoulder form, contrary to trapezius transfer.

In a study by Covey et al, who performed modified the L' Episcopo procedure where latissimus dorsi tendon was rerouted anteriorly to humerus and then anastomosed to teres major tendon routed posteriorly, the average increase in abduction and external rotation were $26^{\circ}$ and $29^{\circ}$, respectively. ${ }^{13}$ This procedure has commonly been used in obstetric brachial plexus injury sequelae; four of the patients in our study sustained pan plexus injuries and hence the latissimus dorsi muscle would not be available; further, in the five patients with a C5, 6, 7 lesion, the muscle would have been less than grade IV, making it a poor choice for tendon transfer.

Narakas has described levator scapulae as the best tendon transfer in the palsy of spinati, elongated with a periosteal strip in children, or fascia lata in adults, passing under the acromion. This modification of Saha's method is quite efficient in the presence of a strong deltoid..$^{14} \mathrm{He}$ achieved an increase of shoulder abduction of $36^{\circ}$ (extremes $18^{\circ}$ and $70^{\circ}$ ).

In our study, the results were better in upper plexus group (-Tables 5 and $\mathbf{6}$ ) on account of presence of deltoid muscle (-Figs. 8-13). The levator scapulae on account of its size, excursion, and tension is best suited to augment or replace the function of the supraspinatus muscle.

\section{Conclusion}

Transfer of levator scapulae tendon to the supraspinatus is an option to improve shoulder abduction in posttraumatic brachial plexus injuries; this is especially so in patients where the trapezius has been denervated consequent to an earlier SAN harvest for an unsuccessful neurotization.

This transfer can be considered in following clinical situations:

1. Where supraspinatus is denervated and deltoid is innervated, levator scapulae transfer can be considered as a best tendon transfer procedure.

2. In partially recovered patients, this transfer helps to augment the supraspinatus and improve range of motion (ROM) of shoulder abduction.

3. In pan plexus injuries, this transfer helps to correct the glenohumeral subluxation and improve ROM of shoulder abduction to some extent. 


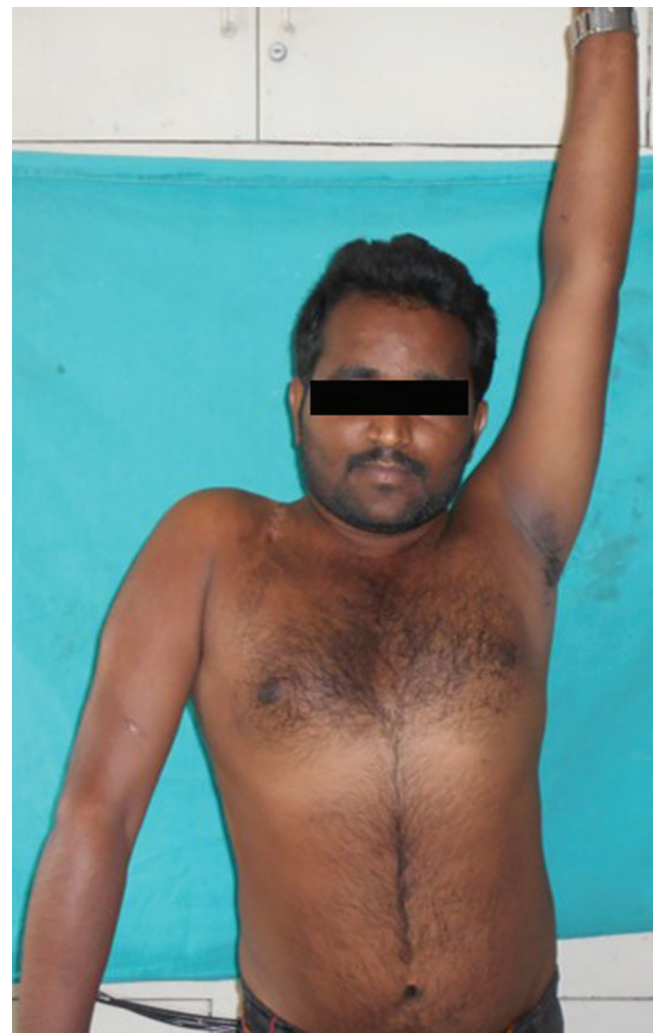

Fig. 8 Preoperative picture in front view demonstrating no shoulder abduction in a patient with isolated C5 lesion.

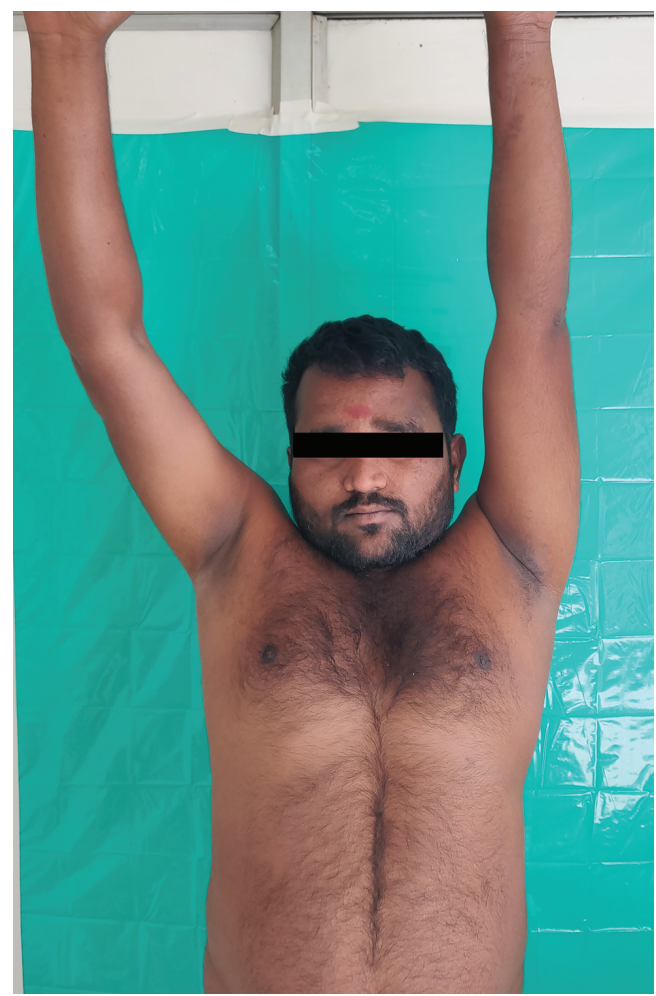

Fig. 9 Postoperative picture in front view demonstrating $155^{\circ}$ of shoulder abduction in a patient with isolated C5 injury.

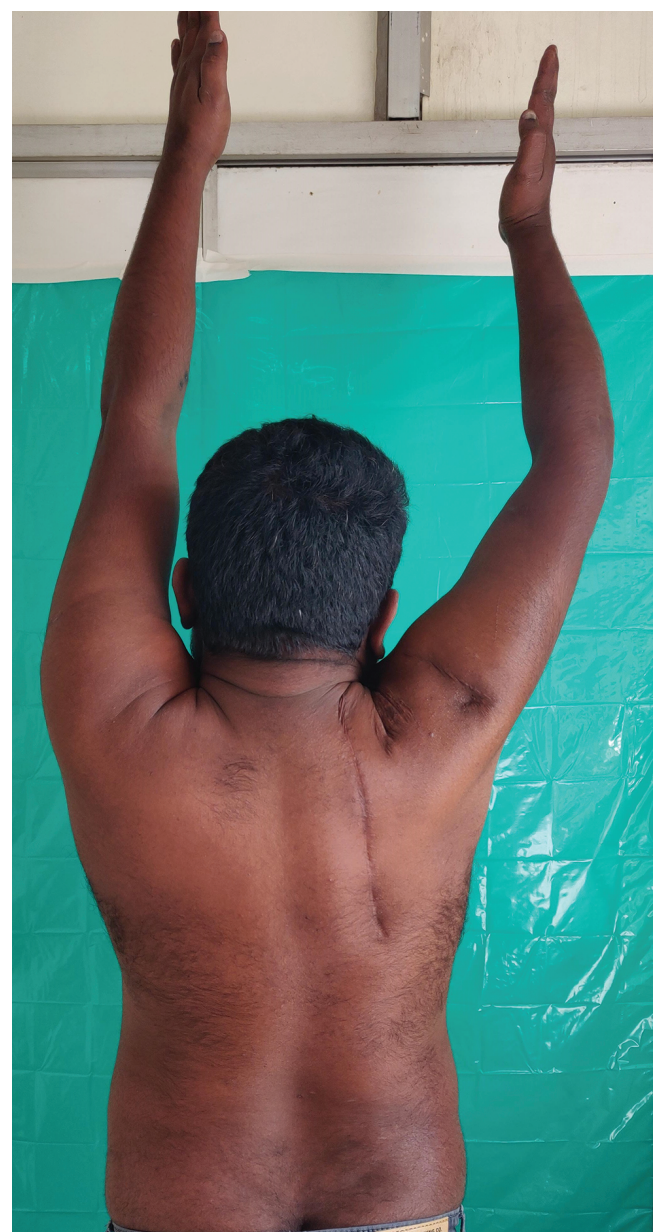

Fig. 10 Postoperative picture in back view demonstrating $155^{\circ}$ of shoulder abduction in a patient with isolated C5 injury.

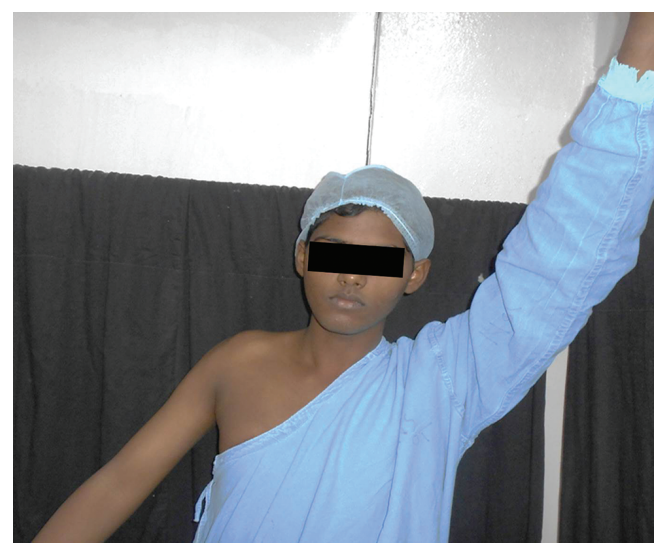

Fig. 11 Preoperative picture in anterior view demonstrating $30^{\circ}$ of shoulder abduction in a patient with C5 injury 


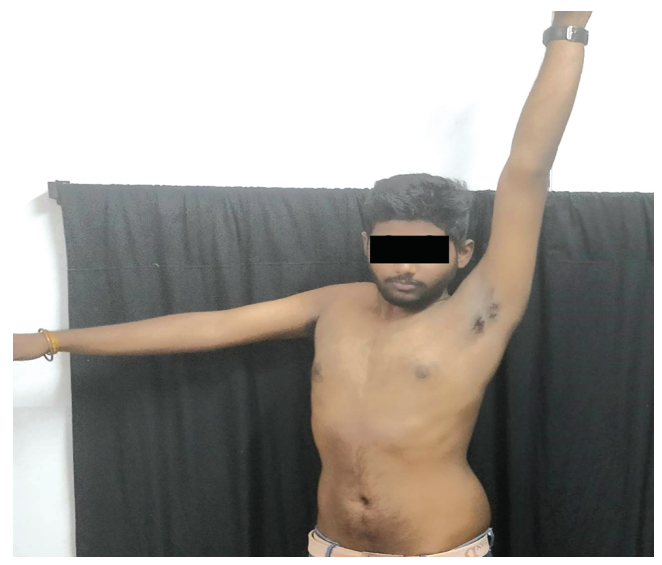

Fig. 12 Postoperative picture in anterior view demonstrating $110^{\circ}$ of shoulder abduction in a patient with C5 injury

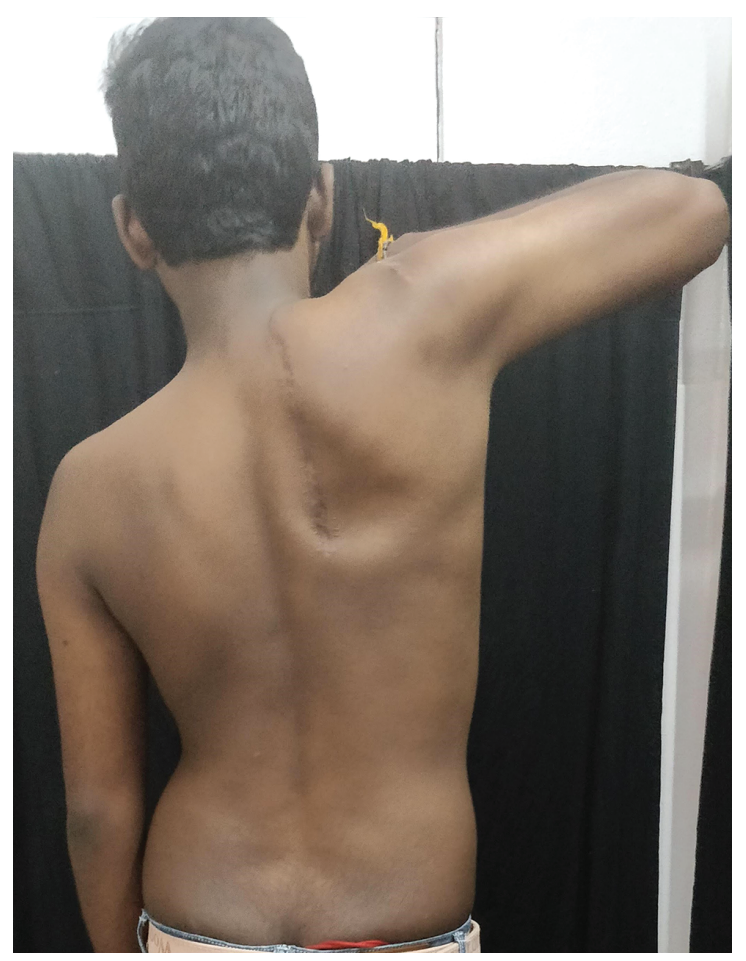

Fig. 13 Postoperative picture in posterior view demonstrating $110^{\circ}$ of shoulder abduction in a patient with $\mathrm{C} 5$ injury.

\section{Future Perspective}

Levator scapulae to supraspinatus can be considered in obstetric brachial plexus injury patients and combined with other muscle transfers for the improvement of external rotation in both adult and pediatric groups.

\section{Conflicts of Interest}

None declared.

\section{References}

1 Elhassan B, Bishop A, Shin A, Spinner R. Shoulder tendon transfer options for adult patients with brachial plexus injury. J Hand Surg Am 2010;35(7):1211-1219

2 Neer CS, Hawkins RJ. A functional analysis of shoulder fusions. J Bone Joint Surg 1977;59B:508-510

3 Cofield RH, Briggs BT. Glenohumeral arthrodesis. Operative and long-term functional results. J Bone Joint Surg Am 1979;61(5):668-677

4 Richards RR, Waddell JP, Hudson AR. Shoulder arthrodesis for the treatment of brachial plexus palsy. Clin Orthop Relat Res 1985;(198):250-258

5 Waters PM. Update on management of pediatric brachial plexus palsy. J Pediatr Orthop 2005;25(1):116-126

6 Bertelli JA, Ghizoni MF. Transfer of the accessory nerve to the suprascapular nerve in brachial plexus reconstruction. J Hand Surg Am 2007;32(7):989-998

7 Narakas AO. Muscle transposition in the shoulder and upper arm for sequelae of brachial plexus palsy. Clin Neurol Neurosurg 1993;95(Suppl):89-91

8 Herzberg G, Urien JP, Dimnet J. Potential excursion and relative tension of muscles in the shoulder girdle: relevance to tendon transfers. J Shoulder Elbow Surg 1999;8(5):430-437

9 Aziz W, Singer RM, Wolff TW. Transfer of the trapezius for flail shoulder after brachial plexus injury. J Bone Joint Surg Br 1990;72(4):701-704

10 Ruhmann O, Wirth CJ, Gosse F. Trapezius transfer in deltoid paralysis. Orthopade 1997;26:634-642

11 Kotwal PP, Mittal R, Malhotra R. Trapezius transfer for deltoid paralysis. J Bone Joint Surg Br 1998;80(1):114-116

12 Singh A, Karki D. Modified trapezius transfer technique for restoration of shoulder abduction in brachial plexus injury. Indian J Plast Surg 2007;40(1)10.4103/0970-0358.32662

13 Covey DC, Riordan DC, Milstead ME, Albright JA. Modification of the L'Episcopo procedure for brachial plexus birth palsies. J Bone Joint Surg Br 1992;74(6):897-901

14 Saha AK. Surgery of the paralyzed and flail shoulder. Acta Orthop Scand 1967;97:5-90 